\title{
Gender Differences in Partner Violence in a Birth Cohort of 21-Year-Olds: Bridging the Gap Between Clinical and Epidemiological Approaches
}

\author{
Lynn Magdol, Terrie E. Moffitt, Avshalom Caspi, \\ and Denise L. Newman \\ University of Wisconsin-Madison
}

\author{
Jeffrey Fagan \\ Columbia University
}

\author{
Phil A. Silva \\ University of Otago Medical School
}

\begin{abstract}
This study describes partner violence in a representative sample of young adults. Physical violence perpetration was reported by $37.2 \%$ of women and $21.8 \%$ of men. Correlates of involvement in severe physical violence differed by gender. Severe physical violence was more strongly associated with unemployment, low educational attainment, few social support resources, polydrug use, antisocial personality disorder symptoms, depression symptoms, and violence toward strangers for men than for women. Women who were victims of severe physical violence were more likely than men who were victims to experience symptoms of anxiety. The findings converge with community studies showing that more women than men are physically violent toward a partner and with clinical studies highlighting violence perpetrated against women by men with deviant characteristics.
\end{abstract}

We report a study of partner violence in a large representative sample of New Zealand young adults. Our goals were (a) to document prevalence rates of both perpetration and victimization, (b) to compare prevalence rates between men and women, and (c) to understand gender differences in prevalence by analyzing gender differences in the psychological and social corre-

Lynn Magdol, Terrie E. Moffitt, Avshalom Caspi, and Denise L. Newman, Department of Psychology, University of Wisconsin-Madison; Jeffrey Fagan, School of Public Health, Columbia University; Phil A. Silva, Department of Paediatrics and Child Health, University of Otago Medical School, Dunedin, New Zealand.

This research was supported by Award 94-IJ-CX-0041 from the National Institute of Justice, Office of Justice Programs, U.S. Department of Justice. Additional support was provided by U.S. Public Health Service (USPHS) Grant MH-45070 from the Violence and Traumatic Stress Branch of the National Institute of Mental Health (NIMH), by USPHS Grant MH-49414 from the Personality and Social Processes Branch of NIMH, by the William T. Grant Foundation, and by the William Freeman Vilas Trust at the University of Wisconsin. The Dunedin Multidisciplinary Health and Development Research Unit is supported by the New Zealand Health Research Council.

Points of view in this article are those of the authors and do not necessarily represent the official position of the U.S. Department of Justice.

We are grateful to the Dunedin Unit investigators and staff and to the study members and their families. We also thank Anna Bardone, Mark Brooke, Larry Bumpass, HonaLee Harrington, and Bradley Wright for their critique of an earlier draft of the article.

Correspondence concerning this article should be addressed to Terrie E. Moffitt, Department of Psychology, University of Wisconsin, 1202 West Johnson Street, Madison, Wisconsin 53706. lates of severe partner violence among young adults. By studying these three questions, we sought to bridge the gap between epidemiological studies, which report substantial rates of partner violence by women, and "clinical"' studies (of shelter, treatment, or correctional samples ), which highlight partner violence by men. The National Academy of Sciences Violence Panel has noted the desirability of early intervention for preventing family violence (Reiss \& Ruth, 1993, p. 246). We studied young adults in their initial couple relationships because they offer the best chance of preventing escalation of partner violence into a repetitive pattern of family violence.

\section{What Is the Prevalence of Partner Violence in Young Adulthood?}

Currently, the best available evidence about the prevalence of violence between partners comes from the National Family Violence Surveys (NFVS; Straus \& Gelles, 1986; Straus, Gelles, \& Steinmetz, 1980) and the National Youth Survey (NYS; Elliott, Huizinga, \& Morse, 1985). Estimates from these studies suggest that past-year prevalence rates may be as high as $51 \%$ for "general" violence and $23 \%$ for "serious" violence (Fagan \& Browne, 1994). Some research suggests that prevalence rates are highest among young adults (Straus et al., 1980; U. S. Department of Justice, 1995). If this were true, it would be critical to schedule prevention efforts early in the life course. For assuring healthy relationship formation among young adults and avoiding exposure of young children to parental violence, prevention strategies may need to be implemented before young couples and their children suffer the negative consequences of a violent family environment (Goodman \& Rosenberg, 1987). 
To add to the knowledge base about the prevalence of partner violence among young adults, we report findings from New Zealand using a representative birth cohort of 21-year-old men and women. Although substantial rates of partner violence have been documented in the United States, the question remains as to whether high prevalence is symptomatic of the United States's "culture of violence" or is more universal. Data from other countries can clarify the interpretation of data gathered in the United States, and cross-cultural replication would strengthen our confidence in prevalence estimates. We used the same measurement instrument as previous epidemiological surveys in the United States, the Conflict Tactics Scales (CTS), so that we would be able to provide direct comparisons of partner violence across cultures.

\section{Are There Gender Differences in Prevalence Rates of Partner Violence?}

Epidemiological findings may offer clues about where to search for causal processes. If partner violence is exclusively a male behavior, then the problem may be appropriately framed as "wife battering" or "violence against women" (Dobash \& Dobash, 1979; Walker, 1984; Yllo, 1993), implicating a patriarchal social system as the primary contributing factor to partner violence. In contrast, if female rates of partner violence are substantial, then men and women are both at risk for performing partner violence. Comparable gender rates could implicate a cycle of retaliatory violence, a shared subculture of violence, or individual psychopathology as additional contributing factors to partner violence.

Early studies of partner violence assumed that men's perpetration rates exceeded those of women, in part because these studies relied almost exclusively on clinical samples of women who sought assistance or of men in court-mandated counseling programs (e.g., Gayford, 1975; Rounsaville, 1978). Later surveys using community samples have shown women's rates of violence to be comparable to those of men (O'Leary et al., 1989; Straus \& Gelles, 1986). Such findings have been controversial (Browne, 1993; Kurz, 1993; Pleck, Pleck, Grossman, \& Bart, 1978). To avoid clinical selection bias in the present study, we collected data from a large representative birth cohort of young adults. Our unselected epidemiological sample offers an advantage in that our results describe perpetrators and victims (both men and women) in the population, including, but not limited to, the subset who seek treatment or who are arrested and convicted. We asked respondents about their experiences of both perpetration and victimization as a means of estimating the accuracy of rates for both men and women. We reasoned that if gender differences in self-reports of perpetration were mirrored by gender differences in reports of victimization, then the differences would be unlikely to be artifacts of reporting biases.

\section{Do the Correlates of Perpetration and Victimization Differ by Sex?}

The surprising gender similarity in prevalence rates that has been documented in previous community studies might be better understood in the context of knowledge about gender differences in the characteristics of perpetrators and victims. We examined the proposition of some researchers that measures of partner violence should be interpreted differently depending on the gender of the perpetrator (Campbell, 1993; Kurz, 1993). For example, O'Leary, Malone, and Tyree (1994) found that relationship characteristics are more strongly related to women's than to men's perpetration. We tested the prediction that the personal characteristics of male perpetrators set them apart from female perpetrators.

We selected 13 variables from five life domains that have been robustly linked to partner violence in clinical studies and community surveys: socioeconomic status, social ties, substance abuse, mental health and criminality. Previous research has documented that these domains are important for male-to-female partner violence (Fagan \& Browne, 1994; O'Leary, 1993; Stark \& Flitcraft, 1988; Walker, 1993). We examined these characteristics among men and women to test whether they were also implicated in female-to-male partner violence. If the correlates of partner violence are the same for men and women, the characteristics of female-to-male violence should be the same as the characteristics of male-to-female violence. If the correlates of partner violence differ for men and women, the correlates of male-to-female violence should differ from those of female-to-male violence (i.e., there should be interaction effects between gender and violence).

We sought to bridge the gap between clinical and epidemiological studies by testing the social and psychological correlates of severe partner violence in a representative sample of young adults. We focused on severe acts of physical violence because these acts are most likely to be associated with women being injured and men being adjudicated and are thus most characteristic of clinical samples. We tested the correlates of such violence-and gender differences in these correlates-in an epidemiological sample because such a sample allowed us to compare the characteristics of young adults engaged in violence to norms on these characteristics for the general population of the same age.

\section{Method}

\section{The Dunedin Study Design and Procedures}

The sample for this study was an unselected birth cohort that has been studied extensively for over 20 years as part of the Dunedin Multidisciplinary Health and Development Study. The history of the study has been described in detail by Silva (1990). Briefly, the study is a longitudinal investigation of the health, development, and behavior of a complete cohort of births between April 1, 1972, and March 31. 1973, in Dunedin, New Zealand (population, 120,000). Perinatal data were obtained at delivery, and when the children were later traced for followup at age $3,1,037$ ( $91 \%$ of the eligible births, of whom $52 \%$ were boys and $48 \%$ were girls) participated in the assessment, forming the base sample for the longitudinal study. With regard to social origins, the children's fathers were representative of the social class distribution in the general population of similar age in New Zealand. With regard to racial distribution, the study members are of predominantly European ancestry, which matches the ethnic distribution of New Zealand's South Island. The Dunedin sample has been reassessed at ages 3, 5, 7, 9, 11, $13,15,18$, and 21 . In this article, we report data gathered from study members at age 21 .

At the age- 21 assessment, each study member came into the research unit within 60 days of his or her birthday for a full day of individual data collection. The various research topics were presented as standardized 
modules by different trained examiners in counterbalanced order throughout the day (e.g., demographics interview, mental health interview, partner relations interview). The set of questions about partner violence was embedded in a 50-min standardized interview about intimate relationships conducted by female interviewers. Although this was the first time that study members were asked about partner violence, they had, in the past, repeatedly reported to us on sensitive topics such as sexual behavior. Because there has never been a violation of confidentiality, they were willing to provide frank reports.

\section{The Sample for the Study of Partner Violence}

Of the 1,037 original study members, 941 provided data about their intimate relationships at age 21 . Data were missing for 17 study members who had died since age $3 ; 9$ who were not located; 19 who refused to participate in the age-21 assessment; 9 for whom there were too many missing items to be included in our analysis; and 42 who were interviewed in the field or by telephone with a short version of the protocol that did not include questions about partner violence. The 941 study members who participated in the intimate relations interview were compared with the 96 study members from the original birth cohort of 1,037 who did not. The two samples did not differ in sex composition $\chi^{2}(1$, $N=1,037)=1.33, p=.25$; social class at birth, $t(939)=0.78, p=$ .44; or history of aggression as measured at age $15, t(958)=0.26, p$ $=.79$. It is thus unlikely that systematic attrition biases our results.

For the purposes of our research, an intimate relationship was defined as a relationship with a romantic partner during the past 12 months that had lasted at least 1 month. Of the 941 study members, $83 \%$ reported that they were involved in an intimate relationship during the past 12 months. These study members were asked about partner violence in reference to their intimate partner. Study members who had more than one intimate relationship in the past 12 months reported about their current or most recent partner. Another $8.5 \%$ of the study members who reported that they were not involved in an intimate relationship that met our criteria during the past 12 months, but that they had dated at least once or twice a month during the past 12 months, were asked about partner violence in reference to their dating experience. Study members who were not involved in an intimate relationship during the past 12 months and who reported that they had never dated during that time ( $n$ $=80$ ) could not be asked about partner violence. In all, we obtained data about partner violence from 861 study members.

Of the 861 study members who were interviewed about partner violence, $71 \%$ were in dating relationships, $26 \%$ were in cohabiting relationships, and $3 \%$ were married. The average length of the relationships about which the study members reported was 16.7 months ( $S D=$ 17.33). Sixty percent of the relationships had lasted for more than 6 months, $44 \%$ had lasted for more than 12 months, and $26 \%$ had lasted for more than 2 years.

\section{Measuring Partner Violence}

Partner violence at age 21 was measured using the CTS (Straus, 1990c). The CTS have been used in numerous clinical studies as well as in U.S. national surveys of the prevalence of marital violence (Elliott et al., 1985; Straus \& Gelles, 1986; Straus et al., 1980). We report CTS scores because they allow us to compare the Dunedin findings to those from nationally representative surveys of Americans. Study members were asked to enter their responses to each question on a private answer sheet while the interviewer read each item aloud. Following Hornung, McCullough, and Sugimoto (1981), the respondents answered the CTS twice. First, they reported about their behavior toward their partner (perpetration), and later they reported about their partner's behavior toward them (victimization).
For comparability with other surveys, we report data about conflict behavior items from Form R of the CTS (Straus, 1990c). As shown in Table 1, the CTS measure of Verbal Aggression includes seven items; the CTS measure of Minor Physical Violence includes three items; the CTS measure of severe physical violence includes six items. In addition, consistent with previous published reports, we report the CTS measure Any Physical Violence, which refers to any of the minor or severe violence behaviors. To be consistent with previous surveys, we considered an individual to have been a perpetrator of verbal aggression, minor physical violence, severe physical violence, or any physical violence if he or she reported engaging in any of the construct-relevant behaviors during the past 12 months. Similarly, individuals were considered to have been victims of verbal aggression, minor physical violence, severe physical violence, or any physical violence if they had any of the construct-relevant behaviors done to them in the past 12 months. The psychometric properties of the scales have been described in detail by Straus $(1990 \mathrm{a}, 1990 \mathrm{c})$.

\section{Correlates of Partner Violence}

In the present study, we examined 13 correlates of partner violence in five domains, as suggested by previous research.

Socioeconomic status. There were two indicators of socioeconomic status. Unemployment was measured by the total number of months of unemployment since leaving secondary school, reported on the Life History Calendar (Freedman, Thornton, Camburn, Alwin, \& YoungDeMarco, 1988). Level of education was measured by a 5-point scale relevant to 21-year-olds in the New Zealand educational system ( $1=$ no school qualification, 5 = university entrance examinations).

Social ties. There were three indicators of social ties. Social support resources were measured by a series of questions drawn from published instruments (Barrera, 1981; Marziali, 1987; Norbeck, Lindsey, \& Carrieri, 1981; Power, Champion, \& Aris, 1988; Reis, 1988; Sarason, Levine, Basham, \& Sarason, 1983; Vaux et al., 1986; Vaux, Riedel, \& Stewart, 1987 ) about the availability of tangible support, emotional support, companionship, and information or advice (e.g., "If you were sick in bed for several weeks, is there someone who would help you?" "Is there someone you can count on to listen when you truly need to talk?"). The measure was the total number out of 37 items for which support was available ( $\alpha$ $=.95$ ). Social involvement was measured by the number of groups and organizations in which the respondent was involved during the past year. The list included II types of groups such as social clubs, religious groups, service organizations, sports teams, hobby groups, and political organizations. Religiosity was measured with one item that asked how important religion was to the respondent. The four response options ranged from not at all important (1) to very important (4).

Substance abuse. There were two indicators of substance abuse. Alcohol abuse was measured with a scale consisting of 23 items drawn from the National Institute of Mental Health (NIMH) Diagnostic Interview Schedule (Robins \& Regier, 1991), an interview that assesses the criterion symptoms of mental disorders in accordance with the Diagnostic and Statistical Manual of Mental Disorders (3rd ed., revised; DSMIII-R; American Psychiatric Association, 1987). Items included symptoms of impairment in daily functioning such as neglect of work, school, or household responsibilities as a result of drinking; objections raised by others to one's drinking; and injury resulting from drinking. Other items reflected symptoms of dependence such as physical tolerance, attempts to reduce or abstain from drinking, and physiological signs of alcohol withdrawal. Variety of drugs used was the number of different types of drugs the respondent reported using within the past year from a list including marijuana, opiates, stimulants, sedatives, and psychedelics.

Mental health. There were four indicators of mental health. All were computed from the NIMH Diagnostic Interview Schedule. The Anxiety scale comprised 19 separate items that represented a range of anxiety 
Table 1

Partner Violence Among 21-Year-Old Women and Men: Perpetration Rates

\begin{tabular}{lccc}
\hline \multicolumn{1}{c}{ Subscale and item } & $\begin{array}{c}\text { Women } \\
(n=425)\end{array}$ & $\begin{array}{c}\text { Men } \\
(n=436)\end{array}$ & $\chi^{2}(1, N=861)^{\mathrm{b}}$ \\
\hline Verbal aggression & $94.6 \%$ & $85.8 \%$ & $18.77^{* *}$ \\
d. Insult or swear & 66.8 & 53.2 & $16.61^{* *}$ \\
e. Sulk or refuse to talk & 59.5 & 52.0 & $5.00^{*}$ \\
f. Stomp out & 52.9 & 42.3 & $9.76^{* *}$ \\
g. Cry & 87.8 & 48.3 & $153.52^{* *}$ \\
h. Do or say something to spite & 46.6 & 43.9 & 0.62 \\
I. Threaten to hit or throw & 24.0 & 10.3 & $28.29^{* *}$ \\
j. Throw-smash-hit object & 14.4 & 18.4 & 2.56 \\
Minor physical violence & $35.8 \%$ & $21.8 \%$ & $20.36^{* *}$ \\
k. Throw object at partner & 10.8 & 3.9 & $15.14^{* *}$ \\
l. Push-grab-shove partner & 28.5 & 20.7 & $7.03^{* *}$ \\
m. Slap partner & 19.1 & 6.0 & $33.77^{* *}$ \\
Severe physical violence & $18.6 \%$ & $5.7 \%$ & $33.34^{* *}$ \\
n. Kick-bite-hit with fist & 14.4 & 4.4 & $25.40^{* *}$ \\
o. Hit with object & 8.3 & 1.1 & $24.42^{* *}$ \\
p. Beat up & 0.9 & 1.1 & \\
q. Choke-strangle & 0.0 & 1.4 & \\
r. Threaten with knife-gun & 0.5 & 0.0 & \\
s. Use knife-gun & 0.2 & 0.0 & $24.35^{* *}$ \\
Any physical violence & $37.2 \%$ & $21.8 \%$ & \\
\hline
\end{tabular}

Note. This table excludes 35 women and 45 men who were not involved with a partner during the year before the interview date.

${ }^{a}$ Items are lettered as in the Conflict Tactics Scale, Form $R$ (Straus, 1990c). ${ }^{b}$ For Items p, q, r, and s, chi-square tests of significance could not be calculated because a cell contained fewer than five cases.

${ }^{*} p<.05 .{ }^{* *} p<.01$.

symptoms including somatic sensations of tension, autonomic hyperreactivity, and behaviors indicative of excessive vigilance (e.g., exaggerated startle response, feeling keyed up or on edge, difficulty concentrating). The Depression scale contained 34 items including the presence of depressed, irritable, or anhedonic mood; changes in sleep, appetite, and weight; symptoms of psychomotor slowing or agitation; difficulties with concentration or decision making; low self-esteem; hopelessness; inappropriate guilt; and recurring thoughts of death or suicide. The Mania scale contained nine items symptomatic of a euphoric or irritable mood, agitation or excessive energy, pressured speech, racing thoughts, decreased need for sleep, increased libido, and grandiose delusions. The Psychosis scale was made up of eight items. Psychotic symptoms assessed included delusions and hallucinations.

Criminality. There were two indicators of criminality. The scale for $D S M-I I I-R$ antisocial personality disorder contained 10 items. These included a history of conduct disorder before age 15 , irresponsible negligence toward family and work, illegal behaviors, fighting, financial mismanagement, lying, conning, and recklessness. Stranger violence was measured during individual interviews with a modified version of the standardized instrument developed by Elliott et al. for the NYS (Elliatt et al., 1985). The measure of stranger violence indicates how many of five different offenses the respondent committed at least once during the past 12 months: simple assault, aggravated assault, rape, robbery, and gang fighting. Questions about these offenses referred to acts that took place outside the home and that excluded partners as victims.

\section{Results}

\section{The Prevalence of Partner Violence: Sex Differences in Perpetration Rates}

Table 1 displays prevalence rates of partner violence by the gender of the perpetrator, for both individual CTS items and the
CTS scales. The discussion here focuses on the scales. Almost all women (94.6\%) reported that they had performed an act of verbal aggression against a partner, as had a large majority of the men $(85.8 \%)$. Physical violence was less common but still substantial, with almost 2 of 5 women $(37.2 \%)$ and 1 of 5 men $(21.8 \%)$ reporting engaging in some form of physical violence. Severe forms of violence were less prevalent than minor forms, with almost 1 of 5 women (18.6\%) and almost 1 of 15 men $(5.7 \%)$ reporting that they had performed an act of severe physical violence in the past year. The most extreme forms of violence (i.e., beating, strangling, and using weapons) were quite rare, never exceeding $2 \%$.

Table 1 also shows that there were significant gender differences in prevalence rates of partner violence. Prevalence rates of perpetration by women were significantly higher than perpetration rates for men for overall verbal aggression, minor physical violence, severe physical violence, and the combined measure of any physical violence.

\section{The Prevalence of Partner Violence: Sex Differences in Victimization Rates}

Table 2 moves from perpetration rates to victimization rates and again shows prevalence and gender differences. The respondents who were perpetrators in Table 1 are now the victims in Table 2, and were thus reporting on behaviors performed by different individuals. The victimization rates shown in Table 2 echo those reported for perpetration in Table 1. Rates of verbal aggression were quite high, with well over 4 of 5 women $(83.8 \%)$ and men $(89.7 \%)$ reporting having been the victims 
Table 2

Partner Violence Among 21-Year-Old Women and Men: Victimization Rates

\begin{tabular}{|c|c|c|c|}
\hline Subscale and item ${ }^{a}$ & $\begin{array}{c}\text { Women } \\
(n=425)\end{array}$ & $\begin{array}{c}\text { Men } \\
(n=435)\end{array}$ & $\chi^{2}(1, N=861)$ \\
\hline Verbal aggression & $83.8 \%$ & $89.7 \%$ & $6.49 *$ \\
\hline d. Insult or swear & 53.9 & 55.9 & 0.34 \\
\hline e. Sulk or refuse to talk & 53.2 & 59.1 & 3.04 \\
\hline f. Stomp out & 47.1 & 45.6 & 0.18 \\
\hline g. Cry & 49.6 & 78.3 & $76.87 * *$ \\
\hline h. Do or say something to spite & 33.6 & 40.5 & $4.28 *$ \\
\hline 1. Threaten to hit or throw & 12.2 & 16.6 & 3.30 \\
\hline j. Throw-smash-hit object & 17.5 & 12.9 & 3.45 \\
\hline Minor physical violence & $26.1 \%$ & $31.8 \%$ & 3.36 \\
\hline k. Throw object at you & 7.1 & 15.0 & $13.60^{* * *}$ \\
\hline 1. Push-grab-shove you & 24.2 & 18.4 & $4.31 *$ \\
\hline m. Slap you & 6.4 & 23.5 & $49.29 * *$ \\
\hline Severe physical violence & $12.7 \%$ & $21.2 \%$ & $10.88^{* *}$ \\
\hline n. Kick-bite-hit with fist & 9.0 & 18.0 & $14.89 * *$ \\
\hline o. Hit with object & 6.8 & 12.9 & $8.83 * *$ \\
\hline p. Beat up & 2.4 & 1.4 & 1.12 \\
\hline q. Choke-strangle & 2.6 & 1.4 & 1.62 \\
\hline r. Threaten with knife-gun & 0.5 & 1.6 & \\
\hline s. Use knife-gun & 0.2 & 0.2 & \\
\hline Any physical violence & $27.1 \%$ & $34.1 \%$ & $5.01 *$ \\
\hline
\end{tabular}

Note. This table excludes 35 women and 45 men who were not involved with a partner during the year before the interview date.

${ }^{a}$ Items are lettered as in the Conflict Tactics Scale, Form R (Straus, 1990c). ${ }^{\mathrm{b}}$ For Items $\mathrm{r}$ and s, chi-square tests of significance could not be calculated because a cell contained fewer than five cases.

$* p<.05 . \quad * * p<.01$.

of verbal aggression of some kind. One of 4 women (27.1\%) and 1 of 3 men $(34.1 \%)$ said they had been a victim of some form of physical violence by a partner. Severe physical violence victimization was reported by 1 of $8(12.7 \%)$ women and 1 of $5(21.2 \%)$ men.

The gender differences in victimization rates were consistent with those for perpetration rates. As shown in Table 1, women tended to report performing acts of violence at higher rates than men; as shown in Table 2, men tended to report being victims of violence at higher rates than women. In both cases, the implication is that aggression by women toward men exceeded aggression by men toward women.

\section{Cross-National Comparisons Between New Zealand and the United States}

Figure 1 highlights the consistency in prevalence rates of partner violence by men and women, comparing data from our sample to data from the 1985 NFVS and the 1983 NYS. For comparison purposes, we give the perpetration and victimization rates only for young adults (see Figure 1): under age 25 in the NFVS ( $n=397)$ as reported by Fagan and Browne (1994), and under age 24 in the NYS ( $n=477$; Elliott et al., 1985). Because the NFVS and the NYS excluded dating couples, the Dunedin rates are presented first for cohabiting study members only (including married and nonmarried, $n=250$ ), and then for cohabiting and dating individuals combined $(n=861)$. The former rates in the Dunedin study provide direct comparison to the NFVS and the NYS rates.
Figure 1 shows consistency across the three studies, not only in prevalence rates of perpetration and victimization, but in gender differences as well. Across the three studies, the perpetration rates reported by women ranged from $36.4 \%$ to $51.3 \%$ and by men from $21.8 \%$ to $43.0 \%$. In all three studies, perpetration rates were higher for women than for men. Across the three studies, the victimization rates reported by women ranged from $27.1 \%$ to $38.8 \%$ and by men from $26.6 \%$ to $55.8 \%$. The sole inconsistency appears to be in the NFVS victimization reports, where rates for women (29.8\%) were slightly higher than those for men $(26.6 \%)$. A conservative conclusion is that female victimization rates are no higher than male rates.

\section{Do the Correlates of Partner Violence Differ for Men and Women?}

Thus far, we have shown that the prevalence rates of partner violence in young adulthood are remarkably similar in different epidemiological studies. Across these studies women report perpetrating more partner violence than men, and men report more victimization than women. We now turn to the third goal of our study, which is to compare the characteristics of men and women involved in partner violence.

Table 3 shows the mean scores for characteristics of perpetrators and victims of Severe Physical Violence compared to individuals who were not perpetrators and victims, respectively, of severe physical violence. We limited our definition of violence to Severe Physical Violence in an attempt to reconcile epidemiological and clinical findings by focusing on the more extreme 

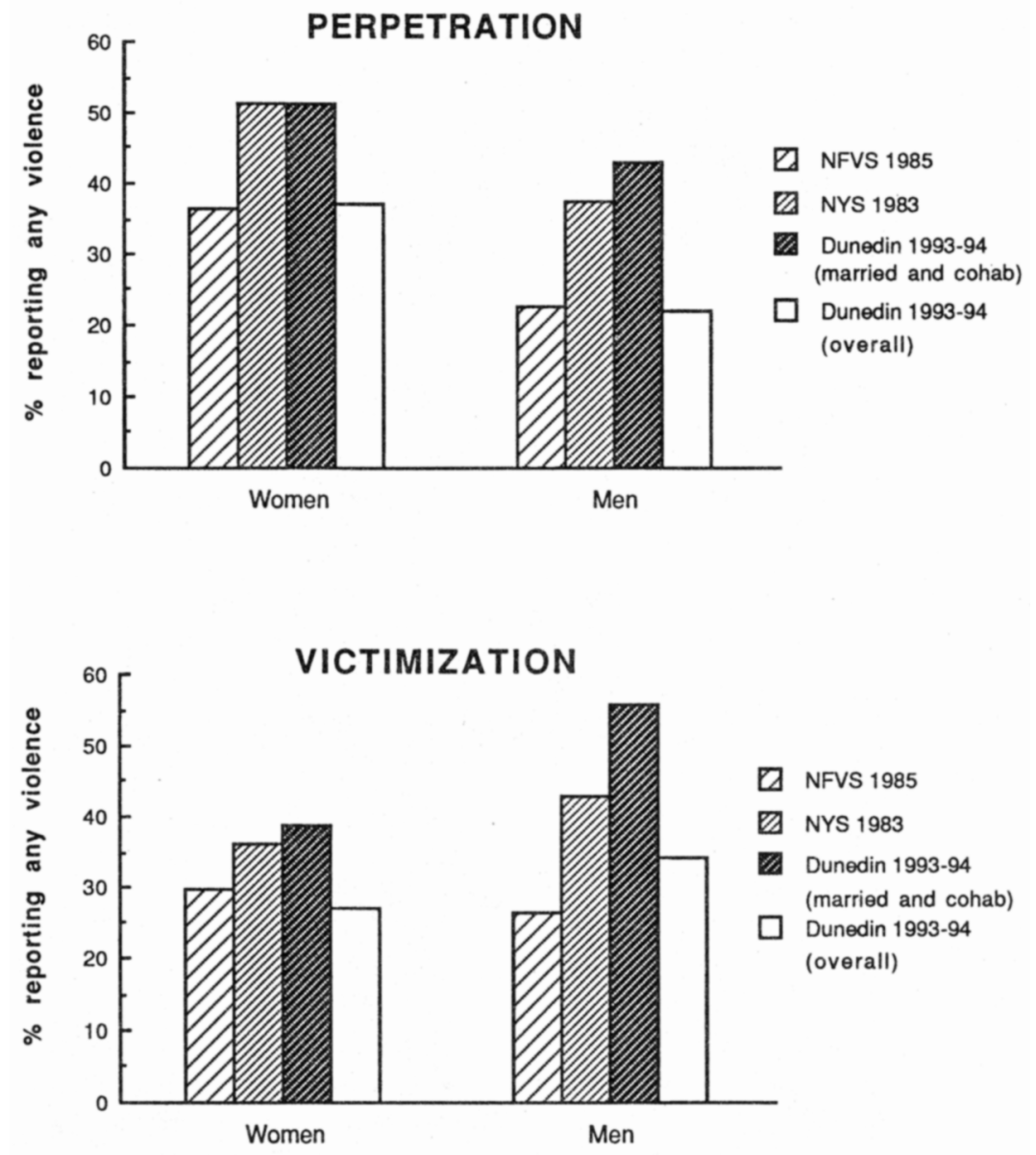

Figure 1. Rates of partner violence in three studies of young adults: the 1985 National Family Violence Survey (NFVS 1985), the 1983 National Youth Survey (NYS 1983), and the 1993-1994 Dunedin Multidisciplinary Health and Development Study (Dunedin 1993-94). cohab = cohabiting.

acts of physical violence; that is, on those acts that may result in women's injury and men's adjudication and that are, thus, most characteristic of clinical samples. The indicators in Table 3 were standardized to a common metric, expressed in $z$ scores, to allow comparison across measures. Because these $z$ scores were standardized on the full representative sample of young adults, the mean $z$ scores allow deduction about how far a group deviates from the general population in standard deviation units. Each of the 13 variables in Table 3 was entered separately into a 2 (male vs. female) $\times 2$ (severe physical violence vs. no severe physical violence) analysis of variance (ANOVA). For each variable in Table 3, we show significant differences between young adults in violent versus nonviolent relationships, between men and women, and significant Gender $\times$ Violence interaction effects. We conducted this analysis twice, once for perpetration reports and once for victimization reports.

Table 3 shows that individuals (both men and women) involved in severe partner violence differed significantly from individuals who were not involved in severe partner violence. Perpetrators and victims had more unemployment and less schooling than study members who were not involved in severe partner violence. Perpetrators and victims reported more symptoms of alcohol dependence and used more different types of illicit drugs than those who were not involved in severe partner violence. For all mental health and criminality scales, scores were significantly higher for study members who were involved in severe partner violence than for those who were not. Thus, symptoms of anxiety disorders, depression, manic disorder, psychosis, antisocial personality disorder, and stranger violence were all associated with partner violence. Having fewer social support resources was significantly associated with victimization and with perpetration by men. Social involvement in organizations and activities was not significantly associated with violence, nor was religiosity.

The characteristics of perpetrators were similar to those of victims in large part because these were the same individuals. Forty-one percent of the women who were perpetrators of severe partner violence were also victims, $\chi^{2}(1, N=425)=67.62$, $p<.001$. Victimized women were 10 times $(95 \%$ confidence interval $[\mathrm{CI}], 5-19)$ more likely to be perpetrators than their nonvictim counterparts. Eighty percent of the men who were perpetrators of severe partner violence were also victims, $\chi^{2}(1$, 
Table 3

Mean Standardized (z) Scores for Characteristics of Perpetrators and Victims of Severe Physical Violence by Sex

\begin{tabular}{|c|c|c|c|c|c|c|c|c|}
\hline \multirow[b]{3}{*}{ Indicator } & \multicolumn{4}{|c|}{ Perpetration } & \multicolumn{4}{|c|}{ Victimization } \\
\hline & \multicolumn{2}{|c|}{ Women } & \multicolumn{2}{|c|}{ Men } & \multicolumn{2}{|c|}{ Women } & \multicolumn{2}{|c|}{ Men } \\
\hline & None & Any & None & Any & None & Any & None & Any \\
\hline $\begin{array}{l}n \text { (range) } \\
\text { Socioeconomic indicators }\end{array}$ & $343-346$ & $73-79$ & $402-411$ & $23-25$ & $363-371$ & $51-54$ & $336-344$ & $88-92$ \\
\hline Unemployment & -.15 & .02 & -.02 & $1.40^{\mathrm{a}, \mathrm{b}, \mathrm{c}}$ & -.17 & .18 & -.08 & $.57^{\mathrm{a}, \mathrm{b}}$ \\
\hline Education & .11 & -.17 & .00 & $-.87^{\mathrm{a}, \mathrm{b}, \mathrm{c}}$ & .11 & -.31 & .05 & $-.42^{\mathrm{a}}$ \\
\hline \multicolumn{9}{|l|}{ Social ties indicators } \\
\hline Social support resources & .20 & .20 & -.03 & $-.97^{\mathrm{a}, \mathrm{b}, \mathrm{c}}$ & .21 & .10 & -.04 & $-.25^{\mathrm{a}, \mathrm{b}}$ \\
\hline Social involvement & .00 & -.08 & .05 & -.17 & .00 & -.09 & .07 & -.07 \\
\hline Religiosity & .10 & .04 & -.13 & $-.20^{\mathrm{b}}$ & .11 & -.06 & -.11 & $-.23^{\mathrm{b}}$ \\
\hline \multicolumn{9}{|l|}{ Substance abuse indicators } \\
\hline Alcohol dependence & -.29 & -.05 & .24 & $.73^{\mathrm{a}, \mathrm{b}}$ & -.30 & .10 & .18 & $.61^{\mathrm{a}, \mathrm{b}}$ \\
\hline Drug variety & -.16 & .12 & .10 & $1.42^{2, b, c}$ & -.15 & .17 & .04 & $.66^{\mathrm{a}, \mathrm{b}}$ \\
\hline \multicolumn{9}{|l|}{ Mental health scales } \\
\hline Anxiety & .05 & .34 & -.11 & $.37^{\mathrm{a}, \mathrm{b}}$ & .04 & .57 & -.11 & $.01^{a, b, c}$ \\
\hline Depression & .14 & .32 & -.18 & $.50^{\mathrm{a}, \mathrm{b}, \mathrm{c}}$ & .11 & .67 & -.22 & $.15^{\mathrm{a}, \mathrm{b}}$ \\
\hline Manic symptoms & -.16 & .21 & .06 & $.48^{\mathrm{a}, \mathrm{b}}$ & -.14 & .26 & .02 & $.33^{\mathrm{a}, \mathrm{b}}$ \\
\hline Psychotic symptoms & -.12 & .31 & -.01 & $.60^{n}$ & -.09 & .35 & -.05 & $.33^{\mathrm{a}}$ \\
\hline \multicolumn{9}{|l|}{ Criminality indicators } \\
\hline Antisocial personality & -.35 & .10 & .19 & $1.48^{\mathrm{a}, \mathrm{b}, \mathrm{c}}$ & -.34 & .25 & .10 & $.88^{2, b}$ \\
\hline Stranger violence & -.37 & .01 & .27 & $.94^{\mathrm{a}, \mathrm{b}}$ & -.33 & -.05 & .17 & $.85^{a, b, c}$ \\
\hline
\end{tabular}

${ }^{\mathrm{a}}$ Violent and nonviolent participants differ at $p<.05$. ${ }^{\mathrm{h}}$ Men and women differ at $p<.05$. ${ }^{\mathrm{c}}$ Gender $\times$ Violence interaction effect is significant at $p<.05$.

$N=436)=55.26, p<.001$. Victimized men were 19 times (95\% CI; 7-52) more likely to be perpetrators than their nonvictim counterparts.

If the correlates of severe physical violence differ for men and women, we would expect to find significant gender interactions. The analysis of severe physical violence in Table 3 showed that six Gender $\times$ Violence interactions for perpetration and two Gender $\times$ Violence interactions for victimization were statistically significant.

All but one of the interactions pointed to more extreme scores for men than for women. Men's mean scores ranged in extremity from 0.5 to $1.5 \mathrm{SD}$ s from the norm for this representative sample of young adults. Men who were perpetrators of severe physical violence had experienced, on average, 20 months of unemployment since leaving school, compared with a full sample average of 6 months. Minimal secondary school credentials (i.e., school certificate examination generally taken in ninth grade) were completed by only $56 \%$ of male perpetrators, compared with $87 \%$ of the full sample. On average, men who were perpetrators had three fewer social support resources than the sample as a whole. In the past year, $72 \%$ of the male perpetrators reported polydrug use (i.e., using two or more types of illicit drugs), whereas the rate for the sample as a whole was $15 \%$. Male perpetrators also reported 6.5 symptoms of depression, compared with an overall sample average of 3.7 , and they reported 3.5 symptoms of antisocial personality disorder, compared with an average of 1.5 symptoms for the sample as a whole. In the past year, $51 \%$ of men involved in severe partner violence as victims had also engaged in violence outside their relationships, compared with $21 \%$ of the full sample. Stranger violence was also common among male perpetrators of severe physical partner violence $(38 \%)$, but the interaction between perpetration and gender did not reach significance at conventional levels.

Only one of the interaction effects pointed to more extreme scores for women than for men. Young women who experienced severe physical violence at the hands of a partner scored $0.5 \mathrm{SD}$ above the norm on anxiety, reporting an average of 2.9 current symptoms, relative to the sample average of 1.4 symptoms. By comparison, the DSM-IV (American Psychiatric Association, 1994) requires the presence of 3 such symptoms for the diagnosis of a Generalized Anxiety Disorder that warrants clinical treatment.

\section{Discussion}

The results of our investigation provide information about the prevalence of partner violence in young adulthood and about gender differences in the characteristics of men and women who participate in severe partner violence. The design of the Dunedin study offered two advantages for this research. First, we gathered information about both perpetration and victimization from a representative sample of young adult men and women who were interviewed about partner violence during the ninth wave of a longitudinal study. Second, we conducted a broadband assessment of the characteristics of individuals involved in partner violence, focusing on multiple spheres of life functioning: socioeconomic status, social ties, substance abuse, mental health, and criminality. Our analysis of the correlates of partner violence thus combines epidemiological and psychosocial approaches.

Our study also has limitations. First, although we provide 
evidence that a considerable proportion of young adults participate in some violence, we did not collect data on the frequency of violent behaviors or on the degree of coercive control and intimidation associated with such violence. Thus, we were limited in our ability to determine the clinical severity of the reported violence and how the severity might differ by gender. Second, we did not collect information about injuries resulting from partner violence. Thus, we cannot draw conclusions about the consequences of violence and how these consequences might differ by gender. Third, the data reported here for partner violence and its correlates are limited to self-reported data. Finally, our description of contemporary correlates of partner violence does not establish the temporal ordering of violence and its correlates (O'Leary et al., 1994). For example, our finding that anxiety is strongly associated with victimization for women does not address whether anxious women are more likely to become victimized or whether victimization makes women anxious. We plan to present prospective longitudinal data from the Dunedin study in the future to address the issue of temporal ordering.

\section{How Common Is Partner Violence?}

Prevalence rates for partner violence perpetration and victimization are substantial among young adults. Our estimates of perpetration rates are $21.8 \%$ for men and $37.2 \%$ for women; estimates of victimization rates are $34.1 \%$ for men and $27.1 \%$ for women. Our estimates are highly consistent with rates for young adults from two large representative surveys that have been conducted in the United States, the NFVS, and the NYS. The consistency in prevalence rates across the three studies is remarkable in light of the many differences among them. The samples in the three studies differed in the types of relationships they sampled. Even when the Dunedin rates are reported for cohabiting couples only, they represent a sample that was predominantly in de facto unions, whereas the NFVS contained predominantly married couples and the NYS contained both. The U.S. studies included respondents between 18 and 25 years of age, whereas the Dunedin study was restricted to 21-yearolds. The three studies differed in the period of measurement; the Dunedin data were collected almost 10 years after the U.S. data. The samples also differed in nationality and race, with the New Zealand sample being almost entirely White, compared with the two U.S. samples, which reflected the racial and ethnic composition of the U.S. population. The studies also differed in methodology. The NFVS administered the CTS as a telephone survey, in contrast to the Dunedin study and NYS, which used face-to-face interviews of study members who had been studied longitudinally for many years and had an accrued relationship of trust with the investigators. The NYS administered the CTS in the context of a survey of criminal behaviors, in contrast to the NFVS and the Dunedin study, which administered the CTS as part of an interview on relationships. Despite all these differences, cross-study results were remarkably similar.

Combining the results of these three studies, it appears that the prevalence rate of partner violence among young adults ranges from $21.8 \%$ to $55.8 \%$. This range is consistent with a recent estimate of $43.8 \%$ from a representative survey of young adults in South Korea (Kim \& Cho, 1992) and with recent young adult samples selected for study on the basis of their intentions to marry (McLaughlin, Leonard, \& Senchak, 1992; O'Leary et al., 1994).

\section{Who Participates in Partner Violence?}

Gender differences in prevalence rates. The present study indicates that at least as many women as men are violent toward their partners. These results corroborate previous surveys of community samples in the United States (Elliott et al., 1985; O'Leary et al., 1989; Straus \& Gelles, 1986). The gender similarities are counterintuitive. What accounts for these results?

First, we considered the possibility that women's self-reports of perpetration might be inflated. Previous studies of partner violence have documented inconsistencies when husbands and wives report on the same behaviors (Browning \& Dutton, 1986; Jouriles \& O'Leary, 1985; Szinovacz, 1983). However, reporting bias seems an unlikely reason for the high levels of partner violence among Dunedin women in light of the finding that women's self-reports of their own perpetration (37.2\%; Table 1) exceeded women's reports of their victimization ( $27.1 \%$; Table 2 ). We can think of no reason why women would be motivated to overestimate their own perpetration while simultaneously underestimating their male partner's perpetration, especially in a longitudinal survey such as ours, where respondents have come to expect neither retribution nor intervention as consequences of their reports. It is, thus, unlikely that reporting biases inflated the women's reports of partner violence.

Second, the expectation that rates of partner violence by men would exceed rates by women may stem from the sampling choices of previous studies. Many of these studies relied on samples of men who had been adjudicated or mandated to treatment programs because of the injurious consequences of their violence (e.g., Faulk, 1974; Hamberger \& Hastings, 1986; Roberts, 1987). Other studies used samples of women who sought shelter or treatment for the injurious consequences of their husband's violence (e.g., Gayford, 1975; Rounsaville, 1978).

It is important to bear in mind that clinical studies and epidemiological surveys historically have asked different questions, and the practical implications of findings from these two types of studies have differed (Johnson, 1995; Straus, 1990b). Clinical studies have the advantage of defining violent cases for study on the basis of serious injury, thereby inherently documenting the consequential nature of the violence studied. However, it is not possible to generalize from such selected samples to draw conclusions about the epidemiology or correlates of partner violence in the population. In contrast, surveys of birth cohorts such as ours, which sample the full range of involvement in partner violence, support generalizable conclusions about the epidemiology and correlates of partner violence. Our findings and other studies (Elliott et al., 1985; Straus \& Gelles, 1986; Straus et al., 1980) have shown women to behave at least as violently as men. However, the interpretation of violent behavior perpetrated by men and women must be informed by knowledge about the consequences of violence, the context in which it occurred, the motives of perpetrators, and their personal characteristics. 
Personal characteristics associated with physical violence. Although we were not able to assess the injury consequences, the context, or the motives related to partner violence, we did examine clinically relevant characteristics of individuals involved in severe partmer violence. Our findings suggest that, although women report more perpetration of physical violence than men, the personal characteristics of male perpetrators are the most deviant and are consistent with the profile that has emerged from clinical research on male perpetrators (Dinwiddie, 1992; Roberts, 1987). Among perpetrators of severe physical violence, men had more extreme levels than did women of clinically relevant characteristics such as polydrug abuse, antisocial personality disorder, and depression. Moreover, severely violent men were more likely than their female counterparts to be poorly educated, chronically unemployed, and to lack social network support. In contrast, women who were victims of severe physical violence were more likely than male victims to suffer clinically significant symptoms of anxiety disorder. This latter finding mirrors that of Stets and Straus (1990) who reported that the difference between victims and nonvictims in stress scores was more extreme for women than for men. The gender differences in characteristics associated with perpetration and victimization support those who view measures of partner violence as having different interpretational contexts for men and women (Kurz, 1993; O'Leary et al., 1994).

This research has bridged a gap between the findings of community and clinical studies regarding gender differences in partner violence. Community studies have consistently reported that more women than men are physically violent toward a partner. Clinical studies have consistently implied that more men than women are physically violent toward a partner. Our findings about severe acts of violence converge with community studies: More women than men were physically violent. Our findings also converge with clinical studies: Physically violent men were far more deviant than physically violent women, and women who were victims suffered far more symptoms of anxiety than men who were victims. These findings suggest that interventions for male-to-female violence must be designed differently from interventions for female-to-male violence.

At least two theoretical perspectives address the pattern in our findings. From one perspective, the rate of violent behaviors may be similar across men and women, but the motivations behind violent behavior and its meanings are thought to differ by gender. Men's physical violence may arise from individual factors in their own lives that threaten their traditional position of dominance: poor education, unemployment, sparse social support, substance abuse, and poor mental health. In direct contrast, women's physical violence may arise not from their own characteristics but from the context of their relationships: for example, the stressful circumstance of being involved with an abusive partner (Campbell, 1993). Men attack, women react. Stets and Straus (1990) tested this hypothesis, but their results were inconclusive. Moreover, this motivational perspective may not offer a complete account of the findings in our own sample because female perpetrators of partner violence differed from nonviolent women with respect to factors that could not be solely the result of being in a violent relationship. If the only factors relevant to women's violence were relationship factors, we would not have expected violent women to differ from nonviolent women on such characteristics as early departure from school, unemployment, or violence against other people.

From another perspective, expectations about the consequences of physical violence influence differently the behaviors of men and women. Research has shown that men's partner violence is more likely than women's to result in injury (Stets \& Straus, 1990). Men may understand that the likelihood is very high that they will injure their partner or be prosecuted and, therefore, men perceive strong reasons to constrain their assaultive behavior. Men's partners are generally younger and weaker, and men's socialization reinforces the rule to restrain violence against targets who are weaker than themselves (Campbell, 1993). If true, fewer men should engage in partner violence than women. In direct contrast, women may understand that the likelihood is very low that they will injure their partner or be prosecuted. Their partners are generally older and stronger; given social norms constraining men's behavior toward women, women may also anticipate that few men will hit back. If true, women may perceive little reason to constrain their assaultive behavior and, therefore, many women should engage in partner violence.

The theoretical perspective that individuals weigh the consequences of violent behavior before deciding whether to express or constrain it is derived from the "rational choice" theory of crime (Becker, 1968; Cornish \& Clarke, 1986). According to this theory, people who should rationally constrain their violent behavior to avoid its serious consequences, but who do not, are people unable to make rational choices. The variables implicated in making irrational choices include the very characteristics we found among men who perpetrate severe physical violence against their partner: being poorly educated, under great economic stress, socially isolated, intoxicated, or suffering a mental disorder. In summary, more women may engage in partner violence than men because partner violence is not such an "irratio. nal" choice for most women in most relationships. Most men are able to make the "rational" choice to constrain their violence, but those relatively few men who have very extreme personal problems may behave irrationally, and thus violently, toward their partners. Future research should explore further both the motivational and rational theoretical perspectives.

\section{References}

American Psychiatric Association. (1987). Diagnostic and statistical manual of mental disorders (3rd ed., rev.). Washington, DC: Author. American Psychiatric Association. (1994). Diagnostic and statistical manual of mental disorders (4th ed.). Washington, DC: Author.

Barrera, M., Jr. (1981). Social support in the adjustment of pregnant adolescents: Assessment issues. In B. Gottlieb (Ed.), Social networks and social support (pp. 69-95). Beverly Hills, CA: Sage.

Becker, G. S. (1968). Crime and punishment: An economic approach. Journal of Political Economy, 76, 169-217.

Browne, A. (1993). Violence against women by male partners: Prevalence, outcomes, and policy implications. American Psychologist, 48, $1077-1087$.

Browning, J., \& Dutton, D. (1986). Assessment of wife assault with the Conflict Tactics Scale: Using couple data to quantify the differential reporting effect. Journal of Marriage and the Family, 48, 375-379. 
Campbell, A. (1993). Men, women, and aggression. New York: Basic Books.

Cornish, D. B., \& Clarke, R. V. (1986). The reasoning criminal: Rational choice perspectives on offending. New York: Springer.

Dinwiddie, S. H. (1992). Psychiatric disorders among wife batterers. Comprehensive Psychiatry, 33, 411-416.

Dobash, R. E., \& Dobash, R. P. (1979). Violence against wives: A case against the patriarchy. New York: Free Press.

Elliott, D. S., Huizinga, D., \& Morse, B. J. (1985). The dynamics of delinquent behavior: A national survey progress report. Boulder: Institute of Behavioral Sciences, University of Colorado.

Fagan, J., \& Browne, A. (1994). Violence between spouses and intimates: Physical aggression between women and men in intimate relationships. In A. J. Reiss, Jr., \& J. A. Roth (Eds.), Understanding and preventing violence: Vol. 3. Social influences (pp. 115-292). Washington, DC: National Academy Press.

Faulk, M. (1974). Men who assault their wives. Medicine, Science, and the Law, 14, 180-183.

Freedman, D., Thomton, A., Camburn, D., Alwin, D., \& Young-DeMarco, L. (1988). The Life History Calendar: A technique for collecting retrospective data. Sociological Methodology, 18, 37-68.

Gayford, J. J. (1975). Wife battering: A preliminary survey of 100 cases. British Medical Journal, 1, 194-197.

Goodman, G. S., \& Rosenberg, M. S. (1987). The child witness to family violence: Clinical and legal considerations. In D. J. Sonkin (Ed.), Domestic violence on trial: Psychological and legal dimensions of family violence (pp. 97-126). New York: Springer.

Hamberger, L. K., \& Hastings, J. E. (1986). Personality correlates of men who abuse their partners: A cross-validation study. Journal of Family Violence, 4, 323-341.

Hornung, C. A., McCullough, B. C., \& Sugimoto, T. (1981). Status relationships in marriage: Risk factors in spouse abuse. Journal of Marriage and the Family, 83, 675-692.

Johnson, M. P. (1995). Patriarchal terrorism and common couple violence: Two forms of violence against women. Journal of Marriage and the Family, 57, 283-294.

Jouriles, E. N., \& O'Leary, K. D. (1985). Interspousal reliability of reports of marital violence. Journal of Consulting and Clinical Psychology, 53, 419-421.

Kim, K., \& Cho, Y. (1992). Epidemiological survey of spousal abuse in Korea. In E. C. Viano (Eds.), Intimate violence: Interdisciplinary perspectives (pp. 277-282). Washington, DC: Hemisphere.

Kurz, D. (1993). Physical assaults by husbands: A major social problem. In R. J. Gelles \& D. R. Loseke (Eds.), Current controversies on family violence (pp. 88-103). Newbury Park, CA: Sage.

Marziali, E. A. (1987). Development of a social support measure for predicting psychotherapy outcome. Journal of Nervous and Mental Disease, 175, 327-338.

McLaughlin, I. G., Leonard, K. E., \& Senchak, M. (1992). Prevalence and distribution of premarital aggression among couples applying for a marriage license. Journal of Family Violence, 7, 309-319.

Norbeck, J. S., Lindsey, A. M., \& Carrieri, V. L. (1981). The development of an instrument to measure social support. Nursing Research, $30,264-269$.

O'Leary, K. D. (1993). Through a psychological lens: Personality traits, personality disorders, and levels of violence. In R. J. Gelles \& D. R. Loseke (Eds.), Current controversies an family violence (pp. 7-30). Newbury Park, CA: Sage.

O'Leary, K. D., Barling, J., Arias, I., Rosenbaum, A., Malone, J., \& Tyree, A. (1989). Prevalence and stability of physical aggression between spouses: A longitudinal analysis. Journal of Consulting and Clinical Psychology, 57, 263-268.

O'Leary, K. D., Malone, J., \& Tyree, A. (1994). Physical aggression in early marriage: Prerelationship and relationship effects. Journal of Consulting and Clinical Psychology, 62, 594-602.

Pleck, E., Pleck, J. H., Grossman, M., \& Bart, P. B. (1978). The battered data syndrome: A comment on Steinmetz' article. Victimology, 2, 680-683.

Power, M. J., Champion, L. A., \& Aris, S. J. (1988). The development of a measure of social support: The Significant Others Scale (SOS). British Journal of Clinical Psychology, 27, 349-358.

Reis, J. (1988). Factorial analysis of social support. Journal of Clinical Psychology, 44, 876-890.

Reiss, A. J., Jr., \& Roth, J. A. (Eds.). (1993). Understanding and preventing violence: Panel on the understanding and control of violent behavior. Washington, DC: National Academy Press.

Roberts, A. R. (1987). Psychosocial characteristics of batterers: A study of 234 men charged with domestic violence offenses. Journal of Family Violence, 2, 81-93.

Robins, L. N., \& Regier, D. A. (1991). Psychiatric disorders in America. New York: Free Press.

Rounsaville, B. J. (1978). Theories in marital violence: Evidence from a study of battered women. Victimology, 3, 11-31.

Sarason, I. G., Levine, H. M., Basham, R. B., \& Sarason, B. R. (1983). Assessing social support: The Social Support Questionnaire. Journal of Personality and Social Psychology, 44, 127-139.

Silva, P. A. (1990). The Dunedin multidisciplinary health and development study: A fifteen-year longitudinal study. Paediatric and Perinatal Epidemiology, 4, 96-127.

Stark, E., \& Flitcraft, A. (1988). Violence among intimates: An epidemiological review. In V. B. Van Hasselt, R. L. Morrison, A. S. Bellack, \& M. Hersen (Eds.), Handbook of family violence (pp. 293-317). New York: Plenum.

Stets, J. E., \& Straus, M. A. (1990). Gender differences in reporting marital violence and its medical and psychological consequences. In M. A. Straus \& R. J. Gelles (Eds.), Physical violence in American families: Risk factors and adaptations to violence in 8,145 families (pp. 151-165). New Brunswick, NJ: Transaction.

Straus, M. A. (1990a). The Conflict Tactics Scales and its critics: An evaluation and new data on validity and reliability. In M. A. Straus \& R. J. Gelles (Eds.), Physical violence in American families: Risk factors and adaptations to violence in 8,145 families (pp. 49-73). New Brunswick, NJ: Transaction.

Straus, M. A. (1990b). Injury and frequency of assault and the "representative sample fallacy" in measuring wife beating and child abuse. In M. A. Straus \& R. J. Gelles (Eds.), Physical violence in American families: Risk factors and adaptations to violence in 8,145 families (pp. 75-91). New Brunswick, NJ: Transaction.

Straus, M. A. (1990c). Measuring intrafamily conflict and violence: The Conflict Tactics (CT) Scales. In M. A. Straus \& R. J. Gelles (Eds.), Physical violence in American families: Risk factors and adaptations to violence in 8,145 families (pp. 29-47). New Brunswick, NJ: Transaction.

Straus, M. A., \& Gelles, R. J. (1986). Societal change and change in family violence from 1975 to 1985 as revealed by two national surveys. Journal of Marriage and the Family, 48, 465-479.

Straus, M. A., Gelles, R. J., \& Steinmetz, S. K. (1980). Behind closed doors: Violence in the American family. Garden City, NJ: Doubleday.

Szinovacz, M. E. (1983). Using couple data as a methodological tool: The case of marital violence. Journal of Marriage and the Family, $45,633-644$

U. S. Department of Justice. (1995). National Crime Victimization Survey. Violence against women: Estimates from the redesigned survey (Bureau of Justice Statistics Special Report No. NCJ-154348). Washington, DC: Author.

Vaux, A., Phillips, J., Holly, L., Thomson, B., Williams, D., \& Stewart, 
D. (1986). The Social Support Appraisals (SS-A) Scale: Studies of reliability and validity. American Journal of Community Psychology, 14, 195-219.

Vaux, A., Riedel, S., \& Stewart, D. (1987). Modes of social support: The Social Support Behaviors (SS-B) Scale. American Journal of Community Psychology, 15, 209-237.

Walker, L. E. A. (1984). The battered woman syndrome. New York: Springer.

Walker, L. E. A. (1993). The battered woman syndrome is a consequence of abuse. In R. J. Gelles \& D. R. Loseke (Eds.), Current controversies on family violence (pp. 133-153). Newbury Park, CA: Sage.

Yllo, K. A. (1993). Through a feminist lens: Gender, power, and violence. In R. J. Gelles \& D. R. Loseke (Eds.), Current controversies on family violence (pp. 47-62). Newbury Park, CA: Sage.

Received October 24, 1995

Revision received February 2, 1996

Accepted February 2, 1996

\section{Call for Papers: Review of General Psychology}

Review of General Psychology (Peter Salovey, Editor, Yale University), the official journal of APA Division 1, seeks to publish innovative theoretical, conceptual, or methodological articles that cross-cut the traditional subdisciplines of psychology. The journal contains papers that advance theory, evaluate and integrate research literatures, provide a new historical analysis, or discuss new methodological developments in psychology as a whole. Review of General Psychology is especially interested in papers that bridge gaps between subdisciplines in psychology as well as related fields or that focus on topics that transcend traditional subdisciplinary boundaries. Intellectual risk-taking is encouraged. Some of the most exciting work in psychology is at the edges of subdisciplines, and traditional journals accommodate such articles only with difficulty; Review of General Psychology is especially interested in these kinds of manuscripts. Papers devoted primarily to reporting new empirical findings are generally not appropriate for this journal.

Review of General Psychology is an official journal of Division 1 (General Psychology) of the American Psychological Association. The target audience for Review of General Psychology is those psychologists who appreciate both generalism as well as specialization and who share a vision of psychology as a unified discipline with common theoretical, methodological, and substantive values. Authors are encouraged to write their manuscripts from the perspective of more than one subdiscipline and to review the literature that spans at least two subdisciplines in order to attract a broad readership. In this era of heightened specialization, Review of General Psychology is committed to the goal of publishing articles from which all psychologists and other social and behavioral scientists can benefit, regardless of subfield or expertise.

Authors should prepare manuscripts according to the Publication Manual of the American Psychological Association (4th edition). All manuscripts must include an abstract containing a maximum of 960 characters and spaces (approximately 120 words). Formatting instructions (all copy must be doublespaced) and instructions on preparing tables, figures, references, metrics, and abstracts appear in the Manual. Manuscripts that exceed 50 pages in length (not including references, tables, and figures) will generally be returned without review.

Submit manuscripts (five copies) to:

Peter Salovey, $\mathrm{PhD}$, Editor

Review of General Psychology

Department of Psychology

Yale University

P.O. Box 208205

New Haven, CT 06520-8205 